\title{
The Effect of Social Media on Fund Returns in China : Empirical Research Based on Rongtong Healthcare Mixed A/B
}

\author{
Helu Mina ${ }^{a}$ Xin Liao ${ }^{b^{*}}$ \\ University of Shanghai for Science and Technology, Shanghai 200093, China \\ amhl300114@163.com, bliaoxin2010@163.com \\ *Corresponding author
}

\begin{abstract}
Social media exerts as an influential force where fund investors can exchange views in real time. The influence may affect fund returns. Focusing on Chinese fund market, this paper examines the influence of social media, eastmoney.com, on the returns of Rongtong Healthcare Mixed A/B fund. We adopt a VAR model, perform the Granger causality test, and analysis the impulse response results. The results highlight the positive influence of social media on fund returns in short term, and there is a unidirectional causality running from the weekly activation and the weekly influence of posts as a whole to fund returns. The paper also reveals that the weekly activation, compared with the weekly influence of posts, has a greater influence on the returns of Rongtong Healthcare Mixed A/B fund.
\end{abstract}

Keywords: Social media, Fund returns, VAR model, Granger causality

\section{Introduction}

Prior literature extensively sheds light on the impact of social media on the financial markets, in particular, the stock market. Antweiler and Frank (2004) ${ }^{[1]}$ present a survey of Internet stock market boards and stock returns. Using computational linguistics methods to measure the sentiment of the media, they find that the messages posted can be predictive of stock market volatility. The influence is statistically significant while it is economically small. Bollen, Mao, and Zeng (2011) ${ }^{[2]}$ analyze the social media from the text content of daily Twitter by mood tracking tools, and demonstrate that public mood states can predict the changes in closing values of the Dow Jones Industrial Average. Leitch and Sherif (2017) ${ }^{[3]}$ measure Twitter reactions for announcements of CEO succession by Twitter sentiment score, and find that the Twitter sentiment has a negative contemporaneous relationship with stock returns and CEO succession announcements. Broadstock and Zhang (2019) ${ }^{[4]}$ also collect social media messages from Twitter, and address that the stock returns are susceptible to the media sentiment. Gu and Kurov (2020) ${ }^{[5]}$ consider firm-specific sentiment with Twitter messages, and find that Twitter sentiment can predict stock returns without subsequent reversals. Guan, Liu, and Cheng (2021) ${ }^{[6]}$ examine the market sentiments through social media to predict the stock market performance after the widely spread of novel Coronavirus disease, and emphasize that the market sentiment towards the pandemic has greatly impacted the stock price difference. In context of the fund market, Lee and Chen (2020) ${ }^{[7]}$ explore the relationship between social media and cross-border ETF returns by using quantile regression. They present empirical evidence that Twitter and U.S. trading market happiness sentiments are significant predictors of ETF returns.

As discussed above, social media can significantly affect financial returns including stocks and funds. However, relative studies in Chinese fund market still remain scant. As for Chinese financial markets, funds, serving as a new engine, have attracted investors' attention. Meanwhile, the openness and inclusiveness of social media help Chinese investors follow financial news in real time and interact with other investors at any time. Posts, comments and other content with a strong emotional preference published on the social network platform will also have a biasing impact on other netizen investors, influencing their trade behaviors, thereby affecting the fund returns. Therefore, it is of paramount significance to study the impact of social media on Chinese fund returns. To fill the gap, we focus on Chinese fund market, and investigate whether the social media, eastmoney.com, affects the returns of Rongtong Healthcare Mixed A/B fund. 


\section{Data and methodology}

\subsection{Data}

This paper selects Rongtong Healthcare Mixed A/B, Rongtong fund for short. With the crawler "Octopus Data Collector", we collect posts about Rongtong fund on the social media: https://fund.eastmoney.com/, which exists as one of the large financial security websites in China. Our sample includes 2326 posts during 17th April 2020 to 26th March 2021, where each post contains four indices: the post body, the author, released time and number of readers. The data frequency in this paper is weekly. So, the fund returns are calculated by Friday's closing prices which are from Wind-Financial Terminal.

\subsection{The fund returns}

In the paper, the fund returns $r_{t}$ is presented as:

$$
\mathrm{r}_{\mathrm{t}}=\ln \left(\mathrm{P}_{\mathrm{t}}\right)-\ln \left(\mathrm{P}_{\mathrm{t}-1}\right)
$$

where $P_{t}$ is a vector of the fund's closing price in week $t$. The fund is losing money at period $t$ for $r_{t}<$ 0 , while the fund is profitable for $r_{t}>0$.

\subsection{Social media}

Referring Chen and Su (2017) ${ }^{[8]}$, we use sentiment index to define the weekly activation $\left(\mathrm{Ac}_{\mathrm{t}}\right)$ and the weekly influence of posts $\left(\mathrm{In}_{\mathrm{t}}\right)$ which measure the influence of social media in week $\mathrm{t}$. Based on the posts of Rongtong fund collected from http://fund.eastmoney.com/, we define sentiment index $\mathrm{M}_{\mathrm{t}}$ as follows:

$$
\mathrm{M}_{\mathrm{t}}=\left(1+\mathrm{Np}_{\mathrm{t}}\right) /\left(1+\mathrm{Nn}_{\mathrm{t}}\right)
$$

where $\mathrm{Np}_{t}$ is the number of posts which are labeled with "positive emotions" at period $t$, and $\mathrm{Nn}_{t}$ is the number of posts which are labeled with "negative emotions". The emotion judging method of posts is that three students determine the emotional colors of the posts in accordance with the uniform standards, independent of each other when making decisions. Supposing that it is still unable to judge, the post is regarded as a neutral one. These standards are as follows: Providing that the content of posts contains certain words like "be expected to rise", "feeling good", which are obviously positive, the posts are labeled with "positive emotions". Otherwise, if the content of posts contains certain words like "be expected to fall", "feeling bad", which are obviously negative, the posts are labeled with "negative emotions". Supposing that the posts, such as the official published notes, have no obvious emotions, then they are regarded as being neutral. After making judgment on the emotional colors of the collected posts, we calculate the weekly sentiment index $\mathrm{M}_{\mathrm{t}}$, and retain two decimal places when calculated. Given that the $\mathrm{M}_{\mathrm{t}}$ index is greater than 1, the overall emotional color of the week's posts is "positive emotion". Inversely, if the Mt index is less than 1, it is "negative emotion".

Since the subjective emotions of investors may have a tremendous influence on the dissemination of information posts, investors may get too emotional when fund prices soar or plunge, with the corresponding sentiment index being extremely large or tending to be 0 . Investors are more likely to express their comments, post opinions, and read others' posts in these weeks, compared with the weeks with stable returns. Considering the effect of sentiment index on the amount of posts and affected areas, as discussed by Chen and $\mathrm{Su}(2017)^{[8]}$, we define the weekly activation $\left(\mathrm{Ac}_{\mathrm{t}}\right.$ ) by multiplying sentiment index and the number of posts $\left(\mathrm{Nu}_{\mathrm{t}}\right)$ in week $\mathrm{t}$, and also define the weekly influence of posts $\left(\mathrm{In}_{\mathrm{t}}\right)$ in week t by multiplying the sentiment index and the average amount of each post to be read $\left(\operatorname{Re}_{t}\right)$ in the following:

$$
\begin{aligned}
\mathrm{Ac}_{\mathrm{t}} & =\mathrm{M}_{\mathrm{t}} \times \mathrm{Nu}_{\mathrm{t}} \\
\mathrm{In}_{\mathrm{t}} & =\mathrm{M}_{\mathrm{t}} \times \mathrm{Re}_{\mathrm{t}}
\end{aligned}
$$

\subsection{Vector autoregression model (VAR)}

This paper is aimed to study the influence of social media on the fund returns. We set up a VAR model, which is presented as:

$$
x_{t}=\Gamma_{0}+\sum_{i=1}^{p} \Gamma_{i} x_{t-i}+\varepsilon_{t}
$$


where $x_{t}$ is $\left[\mathrm{r}_{t}, A c_{t}, I n_{t}\right]^{\mathrm{T}}, \Gamma_{i}$ is estimated parameters, $\mathrm{p}$ is the optimal lag length of the differential variable, $\varepsilon_{t}$ is a vector of idiosyncratic errors.

\section{Results}

\subsection{Unit root tests}

The paper tests statistics' stationarity properties by carrying out the Augmented Dicky-Fuller (ADF) unit root test. The original assumed is to be a sequence with unit root existing. Table 1 illustrates that, for the $1 \%$ critical level, the fund returns, the weekly activation, along with the weekly influence of posts are all stationary.

Table 1: Results of unit root tests.

\begin{tabular}{|c|c|c|c|c|}
\hline Series & $\mathrm{p}$ & $\begin{array}{c}\text { ADF test } \\
\text { statistics }\end{array}$ & $\begin{array}{c}1 \% \text { critical } \\
\text { level }\end{array}$ & conclusion \\
\hline $\mathrm{rt}$ & 0.000 & -7.527 & -3.587 & stationary \\
\hline Act & 0.000 & -5.374 & -3.587 & stationary \\
\hline Int & 0.000 & -4.897 & -3.587 & stationary \\
\hline
\end{tabular}

\subsection{The optimal lag order analysis}

After passing the ADF unit root test, we determine the best optimal lag order of the model by combining results of information criteria such as LR, AIC. As listed in Table 2, the lag order with the most marked "*” is the optimal one for VAR model. It reveals that most criteria determine lag 3 as the best lag.

Table 2: Results of the optimal lag order analysis.

\begin{tabular}{|c|c|c|c|c|c|}
\hline Lag & LR & $p$ & FPE & AIC & SBIC \\
\hline 0 & NA & NA & $1.7 \mathrm{E}+07$ & 25.1718 & $25.291^{*}$ \\
\hline 1 & 21.847 & 0.009 & $1.6 \mathrm{E}+07$ & 25.0881 & 25.5652 \\
\hline 2 & 17.386 & 0.043 & $1.6 \mathrm{E}+07$ & 25.1015 & 25.9363 \\
\hline 3 & $20.628^{*}$ & 0.014 & $1.5 \mathrm{E}+07^{*}$ & $25.0443^{*}$ & 26.2369 \\
\hline
\end{tabular}

\subsection{Granger causality findings}

To identify the direction of causality between fund returns and social media, the paper tests the Granger causality. Table 3 illustrates that with fund returns serving as the explained variable, we cannot reject the original hypothesis that there isn't a unidirectional causality running from the weekly activation to fund returns, neither from the weekly influence of posts to fund returns. Nevertheless, when the combined significance is tested, the results demonstrate that p-value is less than 0.05 , and show that a unidirectional causality running from the weekly activation and the weekly influence of posts as a whole to the fund returns exists.

Table 3: Results of Granger causality.

\begin{tabular}{|c|c|c|c|c|}
\hline Equation & Excluded & Chi2 & df & Prob>chi2 \\
\hline $\mathrm{r}_{\mathrm{t}}$ & $\mathrm{Ac}_{\mathrm{t}}$ & 1.0023 & 3 & 0.801 \\
\hline $\mathrm{r}_{\mathrm{t}}$ & $\mathrm{In}_{\mathrm{t}}$ & 3.886 & 3 & 0.274 \\
\hline $\mathrm{r}_{\mathrm{t}}$ & $\mathrm{all}$ & 12.708 & 6 & 0.048 \\
\hline
\end{tabular}

\subsection{Vector autoregression analysis}

In this section, we estimate the VAR model with lag order 3, which is presented as:

$$
\begin{aligned}
r_{t}=- & 0.2013535 r_{t-1}-0.236591 r_{t-2}+0.1301893 r_{t-3}+0.0000375 A c_{t-1}+0.0000558 A c_{t-2}- \\
& 0.000034 A c_{t-3}+4.98 \times 10^{-7} \operatorname{In}_{t-1}+4.99 \times 10^{-6} \operatorname{In}_{t-2}-2.59 \times 10^{-7} \operatorname{In}_{t-3}-0.005781(6)
\end{aligned}
$$

According to LM test, Table 4 reveals our acceptance of the original hypothesis that residuals have 
no autocorrelation. Then, according to AR root stability test, Figure 1 illustrates that all eigenvalues of the companion matrix fall in the unit circle. So, the system is stable.

Table 4: Results of LM test.

\begin{tabular}{|c|c|c|c|}
\hline Lag & Chi2 & df & Prob>chi2 \\
\hline 1 & 9.5466 & 9 & 0.38842 \\
\hline 2 & 8.6506 & 9 & 0.47013 \\
\hline & & \\
\hline
\end{tabular}

Figure 1: The root map of the companion matrix.

\subsection{Impulse response results}

To test other variables' response and dynamic propagation when one of the variables gets shocked, we simulate the impulse response of orthogonal functions. Figure 2(a) presents the response of Rongtong fund returns to the shock on the errors of the weekly activation $\left(\mathrm{Ac}_{\mathrm{t}}\right)$, and Figure 2(b) presents the response of Rongtong fund returns to the shock on the errors of the weekly influence of posts $\left(\operatorname{In}_{\mathrm{t}}\right)$.

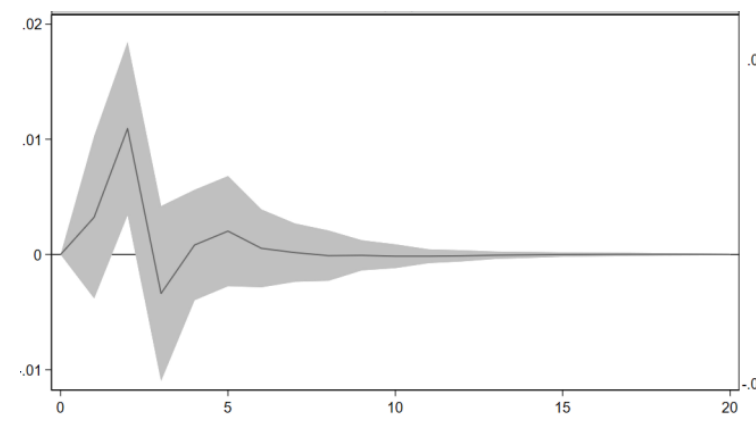

(a). fund returns response to the shock on $A c_{t}$.

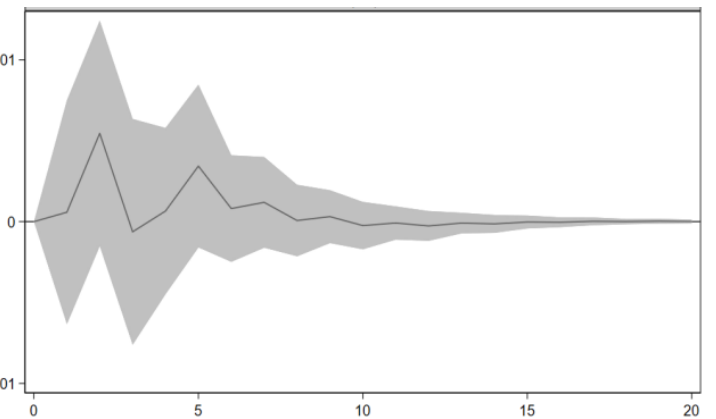

(b). fund returns response to the shock on $\operatorname{In}_{t}$.

Figure 2: Rongtong fund returns impulse response graphs.

As Figure 2(a) shows, when the shock to the weekly activation occurs, Rongtong fund returns respond positively, and the obvious response appears within a short time. The response culminates at the second day, exceeding 0.01 . As time goes by, the response gradually declines with fluctuation, and disappears after about 10 days. As Figure 2(b) illustrates, when the shock to the weekly influence of posts occurs, the general trend of impulse response of Rongtong fund returns is similar as the trend of Rongtong fund returns when the shock to the weekly activation occurs. The positive response appears in a short time, and reaches the top at the second day as well. The response disappears after about 12 days.

Overall, the response illustrates that, fund returns can respond strongly to the weekly activation and the weekly influence of posts for a short time, lasting for only a short period with little continuity. Meanwhile, the response of Rongtong fund returns to the shock on the errors of the weekly activation is stronger than that of the weekly influence of posts. It demonstrates that compared with the influence of posts, Rongtong fund returns respond more vigorously when the weekly activation gets shocked.

The findings above show that Chinese fund investors have herd mentality. The investors are prone to be influenced by peers. Their recognition, judgment, and movement are likely to be led by people around them. Since social media is a main communication platform of investors, the widely-spread posts also 
become an important factor to dominate the trend of investors' decision-making. When fund prices plunge, some investors lose confidence, sell the fund, and post negative opinions on social media. Their behavior may lead to a spread of distrust towards the fund among other investors, even if they did trust the fund before. As a result, massive selling happens, rendering a more dramatic decrease in fund prices. Similarly, when fund prices soar, investors behave on the contrary as they are encouraged to post positive views on social media, believing the returns will reach higher. Thus, they send positive signals to buy more, which make fund price pushed higher with massive buying happening.

\section{Conclusions}

In this study, we have explored the effect of social media on returns of Rongtong Healthcare Mixed A/B fund in Chinese fund market. We collect posts from https://fund.eastmoney.com/, and data covers four indices: the post body, the author, released time, number of readers. Based on the content of investors' posts, we construct sentiment index, and use it to define two variables as proxies for the influence of social media. By establishing the VAR model, we find that there is a unidirectional causality running from the weekly activation and the weekly influence of posts as a whole to the fund returns. Meanwhile, there isn't a unidirectional causality running from the weekly activation to fund returns, neither from the weekly influence of posts to fund returns. In short term, the weekly activation and the weekly influence of posts have a positive effect on the Rongtong fund returns, and the effect has no continuity. As time goes by, the effect gradually declines with fluctuation. Meanwhile, compared with the influence of posts, the weekly activation has a greater influence on Rongtong fund returns.

Overall, we reveal empirical evidence that the social media where investors share ideas and express opinions does have impact on the chosen fund returns in Chinese fund market. The results can provide motivation for fund managers to analyze the content of posts on social media, which may be conducive to performing better in making portfolio selection decisions.

\section{References}

[1] Antweiler, W. and Frank, M.Z. (2004). Is All That Talk Just Noise? The Information Content of Internet Stock Message Boards. The Journal of Finance, 59(3), 1259-1294.

[2] Bollen, J., Mao, H. and Zeng, X.-J. (2011). Twitter mood predicts the stock market. Journal of Computational Science, 2(1), 1-8.

[3] Leitch, D. and Sherif, M. (2017). Twitter mood, CEO succession announcements and stock returns. Journal of Computational Science, 21, 1-10.

[4] Broadstock, D.C. and Zhang, D.-Y. (2019). Social-media and intraday stock returns: The pricing power of sentiment. Finance Research Letters, 30, 116-123.

[5] Gu, C. and Kurov, A. (2020). Informational role of social media: Evidence from Twitter sentiment. Journal of Banking \& Finance, 121, 1-13.

[6] Guan, C., Liu, W.-T. and Cheng, J.Y.C. (2021). Using Social Media to Predict the Stock Market Crash and Rebound amid the Pandemic: The Digital 'Haves' and 'Have-mores'. Annals of Data Science, 1-27.

[7] Lee, C.-C. and Chen, M.-P. (2020) Happiness sentiments and the prediction of cross-border country exchange-traded fund returns. The North American Journal of Economics and Finance, 54, 1-25.

[8] Chen, L.-N. and Su, P. (2017). Empirical Investigation on the Impacts of Social Media on Stock Market. Review of Investment Studies, 36(11), 17-35. 